\title{
A CONTRATAÇÃO DE PESSOAS ACIMA DOS QUARENTA ANOS PRATICADA POR
}

\author{
UMA REDE DE CINEMAS
}

\section{HIRING PEOPLE OVER FORTY YEARS PRACTICED BY A NETWORK OF CINEMAS}

\author{
Andréia Alves da Silva Santana ${ }^{1}$ \\ https://orcid.org/0000-0002-6073-938X \\ Helayne Maria Melo do Nascimento ${ }^{2}$ \\ https://orcid.org/0000-0002-2553-5680 \\ Yohana Karla Ribeiro Vieira ${ }^{3}$ \\ https://orcid.org/0000-0002-6484-9121 \\ Janayna Souto Leal ${ }^{4}$ \\ http://orcid.org/0000-0003-2620-4282 \\ João Batista Soares Neto ${ }^{5}$ \\ https://orcid.org/0000-0003-4311-4297
}

Recebido em: 26 jul. 2020

Aceito em: 23 fev. 2022

Como citar este artigo: SANTANA, A. A. da S.; NASCIMENTO, H. M. M. do; VIEIRA, Y. K. R.; LEAL, J. S.; SOARES NETO, J. B. A CONTRATAÇÃO DE PESSOAS ACIMA DOS QUARENTA ANOS PRATICADA POR UMA REDE DE CINEMAS: HIRING PEOPLE OVER FORTY YEARS PRACTICED BY A NETWORK OF CINEMAS. Revista Visão: Gestão Organizacional, Caçador (SC), Brasil, v. 11, n. 1, p. 18-35, 2022. DOI: 10.33362/visao.v11i1.2329. Disponível em: https://periodicos.uniarp.edu.br/index.php/visao/article/view/2329.

Resumo: Torna-se cada vez mais frequente a adesão de novos projetos de contratação entre empresas que buscam o sucesso. Um exemplo disso é o programa 40+, promovido por uma rede de cinemas. Logo, o presente artigo objetivou analisar como uma rede de cinemas investe

\footnotetext{
${ }^{1}$ Especialista em Gestão de Pessoas pelo Centro Universitário de João Pessoa - UNIPÊ e Graduada em Ciências Contábeis pela Universidade Federal da Paraíba - UFPB. Atualmente, é gestora de Recursos Humanos na empresa de Telecomunicações Tely. E-mail: andreialvesrj@gmail.com.

2 Especialista em Gestão de Pessoas pelo Centro Universitário de João Pessoa - UNIPÊ e Graduada em Administração pela Faculdade Maurício de Nassau. Atualmente, é Assistente de RH na empresa Control Construções. E-mail: helayne.mello@gmail.com.

${ }^{3}$ Graduada em Gestão de Recursos e Especialista em Gestão de Pessoas pelo Centro Universitário de João Pessoa - UNIPÊ. E-mail: yohanavieira.rh@outlook.com.

${ }^{4}$ Aluna do Doutorado em Administração pela Universidade Federal da Paraíba - UFPB. Professora nos Cursos do Bacharelado em Administração, Ciências Contábeis e dos Cursos de Ensino Superior em Tecnologia da Gestão no Centro Universitário de João Pessoa - UNIPÊ e Avaliadora Ad hoc INEP/MEC. E-mail: leal.janayna@gmail.com.

${ }^{5}$ Doutor. Professor adjunto I da Universidade Federal da Paraíba nas áreas de marketing e de comportamento do consumidor, e é um dos líderes da inforMA Grupo de Pesquisa. E-mail: jnetojp@gmail.com.
} 
em um programa de contratação voltada a pessoas acima dos quarenta anos. Metodologicamente, adotou-se a abordagem qualitativa utilizando um roteiro de entrevista estruturado, aplicado a dois gestores. Como método, foi utilizada a análise de conteúdo e as categorias analisadas foram: Modelo de contratação; Mercado de trabalho para a faixa etária acima dos quarenta anos; Acertos e Desafios do Programa 40+. Como resultados, observou-se que a contratação dos funcionários acima dos quarenta anos acaba por melhorar o funcionamento da organização, em virtude das experiências e pelo comportamento maduro apresentado. Conclui-se, portanto, a importância e viabilidade da criação de projetos que valorizam a política de contratação desse público.

Palavras-Chave: Contratação. Acima dos quarenta anos. Rede de cinemas.

Abstract: It is becoming more and more frequent the adhesion of new hiring projects among companies that seek success. An example of this is the 40+ program, promoted by a cinema chain. Therefore, the present article aimed to analyze how a cinema network invests in a hiring program aimed at people over forty years old. Methodologically, the qualitative approach was adopted using a structured interview script, applied to two managers. As a method, content analysis was used and the categories analyzed were: Hiring model; Labor market for the age group above forty years; Hits and Challenges of the 40+ Program. As a result, it was observed that the hiring of employees over forty years ends up improving the functioning of the organization, due to the experiences and mature behavior presented. It is concluded, therefore, the importance and feasibility of creating projects that value the public's hiring policy.

Keywords: Hiring. Above forty years. Cinema network.

\section{INTRODUÇÃO}

Em um contexto em que permeia a competitividade, as empresas que buscam o sucesso e a permanência no mercado têm como propósito recrutar e selecionar talentos de modo a obter uma equipe competente e vencedora, que agregue valores, gere novas ideias e aumente a sua posição no ambiente econômico, a um nível de excelência interna e externa. Para tanto, os profissionais da área dos Recursos Humanos (RH) vem aderindo a técnicas de análise mais tecnológicas e processos seletivos mais assertivos (FAISSAL et al., 2015; SANTOS; LIMA, 2018).

O objetivo dos processos seletivos é contratar os melhores colaboradores para as suas respectivas organização. Contudo, o mercado de trabalho vem enfrentando um cenário complexo e turbulento. Mudanças políticas, econômicas e sociais estão acontecendo significativamente, a exemplo disso seguem a eliminação de postos de trabalho, a precarização do trabalho, a redução de direitos trabalhistas, dentre outros, gerando expansão no mercado informal, diminuindo o trabalho formal e restringindo as opções de contratação.

Partindo desse princípio, é possível observar uma discriminação por parte de profissionais de Recursos Humanos e das organizações, de um modo geral, em relação às 
pessoas acima dos quarenta anos. Um estudo realizado por Abdala (2020), e divulgado pela Empresa Brasil de Comunicação (EBC), órgão do governo federal, comprova esta realidade: adultos com mais de quarenta anos possuem dificuldades para o reingresso no mercado de trabalho, representando $25 \%$ dos desempregados do país. A pesquisa aponta que, mesmo possuindo vivência e experiência, a idade, por si só, geralmente, é um fator que gera preconceito por parte dos empregadores.

De acordo com a Digital Group (2020), as principais dificuldades relacionadas a contratação de candidatos da faixa etária pertencente a Geração X, entre 39 a 58 anos, estão ligadas diretamente a resistência a mudanças. Porém, verifica-se que estes prezam pelo consumo de informação, seja de forma online e/ou offline. Apesar disso, destaca-se ainda que pessoas dessa geração buscam constantemente o autoaprendizado online, por meio de ferramentas disponibilizadas principalmente nos telefones celulares. Vale ressaltar que não existem políticas públicas direcionadas a contratação de pessoas dessa idade, o que acaba tornando-se uma opção da própria empresa em criar projetos com o objetivo de contratação dessas pessoas

Contudo, no intuito de mostrar que este panorama pode apresentar uma outra realidade mais produtiva e inclusiva, o trabalho em questão traz o projeto de uma rede de cinemas que possui um programa denominado " $40+$ ". O referido programa procura, em sua política de contratações, reservar uma cota em seu quadro de funcionários para pessoas acima dos quarenta anos de idade. Um fato interessante é que o preenchimento desta cota não pode ser direcionada apenas para colaboradores que realizam serviços gerais, ela abrange também a área de vendas, com o foco principal no atendimento ao cliente.

Diante do exposto, o presente estudo traz a seguinte problemática: como uma rede de cinemas investe em um programa de contratação voltada a pessoas acima dos quarenta anos?

Como objetivo geral, o artigo busca analisar como uma rede de cinemas investe em um programa de contratação voltada a pessoas acima dos quarenta anos. Atrelados a ele, estão os objetivos específicos que consistem em: Verificar como funciona o processo de Recrutamento e Seleção ( $R$ \& S) adotado pela rede de cinemas para a faixa etária pesquisada; Identificar o alinhamento da política de contratação da organização estudada em relação ao que vem sendo praticado no mercado de trabalho; Examinar as potencialidades e fragilidades encontradas no Programa 40+. 


\section{REFERENCIAL TEÓRICO}

\section{CONTRATAÇÃO: CONCEITOS E PRÁTICAS ADOTADOS}

A contratação de funcionários é um dos pontos mais importantes dentro das organizações e departamentos de Recursos Humanos (RH), pois, conforme preconiza Marques (2016), eles precisam do capital humano para manter-se no mercado. Portanto, para contratar novos colaboradores, as empresas muitas vezes utilizam ferramentas de análise da necessidade do negócio, que consistem em avaliar o déficit de pessoal no quadro.

Contratar funcionários é algo que demanda esforço e planejamento, sendo necessário pensar em uma série de elementos, tais como: quantidade de vagas, descrição do cargo, níveis de responsabilidade e de atuação, pretensão salarial, entre outros, com a finalidade de recrutar os profissionais para uma futura seleção, tendo como base os custos que o processo irá acarretar para a empresa, a sua agilidade e as etapas para efetivar a contratação (CAMPOS; BARSANO, 2016).

Nessse sentido, o recrutamento surge como um processo que tem como objetivo principal suprir a organização de pessoas, quantitativamente e qualitativamente, para o alcance dos seus objetivos. Logo, é um conjunto de técnicas e processos utilizados pelas organizações para a divulgação de vagas de trabalho com o intuito de captar candidatos qualificados e capazes para ocuparem os seus cargos (BANOV, 2015).

Partindo desse pressuposto, subentende-se que o recrutamento é a fase mais importante da admissão de um novo colaborador, uma vez que é a primeira etapa para atrair novos talentos, em que é possível a identificação das habilidades e competências que agregam valor para a empresa. Em outras palavras, utiliza-se desta ferramenta para que se possa ter uma maior probabilidade de acerto em um processo de contratação, e assim construir, consequentemente, times de alta performance.

Para Silva, Leal e Soares Neto (2018), existem dois tipos de recrutamento: o interno e o externo. O recrutamento interno é formado pelo quadro atual de colaboradores da empresa, que busca submeter o colaborador a uma promoção, transferência. Esse processo possui inúmeras vantagens, sendo rápido, econômico e de baixo custo, evitando despesas com a divulgação em veículos externos. O recrutamento externo ocorre quando a organização não possui mão-de-obra com o perfil para vaga, buscando preencher o quadro com pessoas novas que possam trazer vantagens, ideias e experiências. No entanto, tal processo traz custos para a empresa e não oferece garantias de acerto.

Relativamente à seleção, é uma etapa que vem logo após o recrutamento no processo de somar pessoas à organização. Trata-se de um conjunto de ações técnicas que objetivam suprir a necessidade de profissionais em uma organização, ou seja, é o processo pelo qual uma 
organização escolhe, entre uma lista de candidatos, o indivíduo que melhor alcança os critérios para uma posição disponível, considerando as atuais condições do mercado (ORLILKAS, 2001; STOPAZZOLI; PUMARIEGA, 2020).

As técnicas utilizadas para atrair e selecionar pessoal são diversas. Quanto mais o profissional da gestão de pessoas conhece as possibilidades existentes e participa ativamente do processo de contratação, maior será a probabilidade da sua escolha ser mais assertiva, considerando o cargo e a realidade da empresa, em determinado momento. É possível mudar ou aperfeiçoar um modelo aplicado, e esse deve ser o foco do profissional que atua com Gestão de Pessoas: a melhoria contínua dos processos que utiliza (FERREIRA, 2014).

Findadas todas as etapas referentes ao recrutamento e à seleção, é verificado se a organização encontrou, de fato, o(a) candidato(a) apto(a) para assumir a posição disponível, podendo assim proceder à sua contratação. Por ocasião dela, a empresa deve obedecer rigorosamente a uma série de procedimentos para admissão, previstos na legislação vigente (CAMPOS; BARSANO, 2016).

Para Caxito (2007), independente do tipo de processo utilizado para a contratação, o entrevistador deve estar ciente quais os pontos mais relevantes e características dessa vaga, pois assim poderá identificar facilmente o perfil apropriado. O uso das consultorias e redes sociais ajudam no processo de atração e seleção, geralmente adotado para atrair o capital humano externo, visando renovação da cultura, enriquecendo o capital intelectual, além de gerar oportunidade para novas pessoas.

Em suma, de acordo com Figueiras et al. (2018), para obter êxito, consistência e competitividade no mercado, as empresas utilizam e seguem algumas etapas de modo que possam encontrar o candidato mais qualificado. Tais etapas são: o recrutamento dos candidatos; a triagem e análise curricular; aplicação de testes dos mais variados (conhecimento, desempenho e psicológico), entrevista de seleção; exame médico; e, por fim, a admissão.

Logo, todo esse procedimento visa um processo contratual que possa trazer para a empresa um profissional que atenda às demandas organizacionais conforme o seu entendimento, o que muitas vezes torna desafiador perante a dinamicidade do mercado de trabalho e da disponibilidade dos candidatos existentes em uma determinada conjuntura.

\section{MERCADO DE TRABALHO: REINSERÇÃO PARA O PÚBLICO ACIMA DOS QUARENTA ANOS}

Para Faria (2016), o mercado de trabalho é uma junção de oferta e demanda, em que as empresas buscam profissionais qualificados para preenchimento dos seus quadros funcionais e, por outro lado, as pessoas buscam estar inseridas neles. O funcionamento e a dinâmica do mercado de trabalho são de vital importância para o desempenho, o crescimento e a sobrevivência de uma economia. 
$\mathrm{Na}$ atual conjuntura, o cenário que envolve o mercado de trabalho aponta para um número não tão volumoso de ofertas de empregos. Candidatos dos mais diversos perfis em termos de qualificações, altas e baixas rendas, faixas etárias encontram-se à disposição e, em contrapartida, organizações com altas exigências relativas às competências e habilidades aos profissionais que desejam contratar denota um panorama complexo e de difícil entendimento (BANOV, 2015).

Segundo Minarelli (2009), este comportamento adotado pelas empresas remete ao fato de que elas, na contemporaneidade, são adeptas de um novo modelo organizacional, procurando adaptar-se às mudanças exigidas para procedimentos que vão surgindo continuamente. Assim, as pessoas, de um modo geral, passam a representar a principal fonte de recursos das organizações e se tornam colaboradoras e parceiras do negócio da empresa, por isso há existência desse grau de requisitos solicitado por elas.

Nesse ínterim, o profissional e candidato a uma vaga no mercado de trabalho tem que apostar no aumento da sua empregabilidade como forma de garantir um lugar e permanecer inserido no quadro funcional de uma organização. De acordo com Barduchi (2010), empregabilidade representa a capacidade do indivíduo manter-se empregado e conseguir ascensão profissional, em outras palavras, são ações empreendidas pelas pessoas que buscam desenvolver habilidades e conhecimentos necessários para o crescimento profissional.

Diante desse contexto, verifica-se que os indivíduos que pretendem ingressar ou reingressar no universo organizacional estão a frente de uma disputa concorrida e acirrada, pois as demandas solicitadas pelas empresas estão cada vez maiores, o que limita e restringe ainda mais a concorrência. Tal cenário acaba por diminuir consideravelmente as oportunidades dos candidatos com mais idade no mercado de trabalho devido aos mais variados motivos, tais como: o próprio fator idade que gera um preconceito ao contratar, assim como também a falta de atualização a nível das práticas realizadas, seja de forma interpessoal como tecnológica, que pode ser tido com um fator impeditivo de contratação (BULLA; KAEFER, 2003).

Neri (2014) aponta a necessidade dos profissionais maduros transformarem décadas de experiência em competências e inovação para continuarem sendo úteis à sociedade e contribuírem com o seu trabalho para a construção de uma sociedade melhor. De maneira geral, eles não precisam de benemerência, mas sim de oportunidades e treinamento. O autor ainda afirma que, desde que bem aproveitadas, as competências dos trabalhadores maduros permitem que eles atuem no segmento formal, como empregados, prestadores de serviços ou pequenos empresários, professores, consultores e líderes de projetos.

Logo, como alternativa para superar essas dificuldades, são apontados alguns procedimentos a serem seguidos que, possivelmente, podem ser facilitadores para uma viável recolocação profissional, como por exemplo: demonstrar capacidade de suportar "extensas" jornadas de trabalho, assim como também se mostrar atualizado e demonstrar aptidão para a 
atividade a ser realizada (NERI, 2014).

Partindo desse princípio, aos poucos esse quadro vem se modificando. Conforme noticiado pela Folha de São Paulo (2018), algumas empresas, têm adotado programas para a contratação exclusiva de pessoas maduras. Essas iniciativas possuem em comum tanto o fato de serem muito recentes quanto também de terem como foco a contratação em uma faixa etária mais avançada, marcando o início de uma mudança de mentalidade das organizações em relação aos profissionais mais maduros. Na contemporaneidade, o mercado vem assumindo uma nova postura, muito mais voltada à valorização da experiência e da garantia da diversidade das gerações mais experientes dentro do âmbito organizacional. Uma prova disso são os projetos que vêm sendo desenvolvidos como forma de integrar e oferecer vagas destinadas a um público acima dos quarenta anos como, por exemplo, em uma rede de cinemas nacional, que será tratado no tópico a seguir.

PROGRAMA 40+: UM PROJETO DE INSERÇÃO ADOTADO POR UMA REDE DE CINEMAS

De acordo com Raposo e Günther (2008), em todas as fases da vida, as expectativas quanto ao futuro, desejo de progresso e senso de controle são desafiadas continuamente. Em outras palavras, para que o indivíduo mantenha-se alinhado com o seu bem-estar físico e social, torna-se necessário que ele procure estar inserido no mercado de trabalho.

Em meio a concorrência acirrada, instabilidade e novas tecnologias, não tem sido fácil para as pessoas que entram na maturidade permanecerem e perdurarem no mercado de trabalho. Todavia, as organizações têm buscado qualidades e competências atreladas aos perfis comportamentais desse tipo de público. Diante dessa necessidade, novas oportunidades têm surgido, conforme aponta Lajolo (2018), no qual observa-se que algumas empresas já começam a considerar a contratação de candidatos dessa faixa etária por meio da criação de programas exclusivos para contratação dessa mão-de-obra. Iniciativas assim têm demonstrado o início de uma mudança de mentalidade em relação a esses trabalhadores.

Assim, algumas organizações já estão promovendo mudanças em seu mindset e estão buscando um novo acordo de trabalho, talvez não por aumento de sua maturidade moral, mas pelo receio de prejuízos e punições que vão se agravando. É possível afirmar que a demanda social e, consequentemente, legal tem mudado o comportamento das organizações e das pessoas, fazendo com que o comportamento moral e as boas maneiras sejam postas em prática, mesmo que o raciocínio moral continue em estágios anteriores (AYLMER, 2019).

Diante do exposto, cuja contratação de pessoas com mais idade podem também trazer benefícios e vantagens para as organizações, surge um projeto adotado por toda a rede de uma grande empresa multinacional que atua no segmento de cinemas, intitulado "Projeto $40+"$. Este projeto é recente, com início no ano de 2019, tendo como propósito oportunizar pessoas de mais idade, especificamente acima de quarenta anos, em seu retorno ao mercado 
de trabalho.

A inspiração de criação do projeto veio perante uma percepção dos gestores da empresa que identificaram no cenário nacional a dificuldade de reingresso ao mercado de trabalho por parte dessas pessoas, tornando-sed uma aposta interessante e que poderia trazer vários benefícios para a rede de cinemas, tais como: o fator experiência, a maturidade e paciência, a dedicação, além da realização de um trabalho consistente e atuante de responsabilidade social direcionado para uma parcela relevante e contributiva da sociedade.

Nesse sentido, o "Projeto 40+" tem como intuito destinar vagas exclusivamente a funções de Atendente nas seções de bilheteria e bomboniere. Os cargos foram escolhidos devido a um levantamento feito pelos gestores da empresa que verificaram que a contratação de pessoas de mais idade, geralmente, é direcionada, em sua maioria, para cargos de serviços gerais.

Dado que assim como o Projeto 40+, outras iniciativas vêm sendo instituídas no mercado de trabalho a fim de incentivar cada vez mais a contratação de pessoas dessa faixa etária. A exemplo disso, o Programa "Bob's Melhor Idade", o "Atividade", desenvolvido pela empresa Pizza Hut e o "Projeto Retorno ao Trabalho", desenvolvido pela Dedic (empresa de Call Center) (BATISTA, 2016). O autor ainda aponta que, de acordo com registros obtidos por meio desses projetos, as empresas oferecem aos seus funcionários a oportunidade de alcançar cargos melhores, podendo iniciar como atendentes e chegar até a cargos de gerência, configurando em um cenário de possibilidades otimistas para este público.

\section{PROCEDIMENTOS METODOLÓGICOS}

O presente estudo tem como propósito analisar como uma rede de cinemas investe em um programa de contratação voltada para pessoas acima dos quarenta anos. Optou-se por esta temática mediante a análise prévia de pesquisas e práticas profissionais pesquisadas e já mencionadas neste trabalho de que cada vez mais pessoas dessa faixa etária têm buscado adentrar no mercado de trabalho como uma opção possível e viável.

Para tanto, escolheu-se uma rede de cinemas, em que duas de suas unidades atuam na cidade de João Pessoa - PB. Tal decisão se baseou no fato desta ser considerada a maior operadora de cinemas da América Latina, além de ser a segunda maior do mundo quando tratase de números de ingressos vendidos.

A partir deste contexto, adotou-se para este trabalho a abordagem qualitativa. De acordo com Knechtel (2014), este tipo de pesquisa procura compreender fenômenos humanos por meio de uma visão detalhada e complexa realizada através de uma análise científica do pesquisador. Neste tipo de estudo são levados em consideração ainda as principais motivações, crenças e valores apresentados pelo entrevistado. Além disso, foi empregado o uso de estudo 
de caso que, segundo Gil (2008), é caracterizado pelo estudo de um ou de poucos objetos, fazendo com que através dessa análise possa ser conhecido de forma mais ampla e detalhada mais informações sobre ele(s).

No que concerne à coleta de dados, foi utilizado um roteiro de entrevista estruturado com nove perguntas, sendo fundamentado na revisão teórica explorada neste trabalho e também com base nos objetivos específicos elaborados. De acordo com Lakatos e Marconi (2010), este é um roteiro previamente estabelecido, no qual não é permitido adaptar as perguntas, nem inverter a ordem ou elaborar outras perguntas, sendo obrigatório o respeito a sequência das mesmas.

Para tanto, foram empregados o software Google Forms para a sua elaboração e para o envio a ferramenta eletrônica do e-mail, sendo obtidas as respostas entre os dias 26 a 28 de abril de 2020. Tal mecanismo foi usado de modo a garantir maior facilidade e praticidade para os participantes, em decorrência do panorama atual brasileiro, que se mostra frágil e recluso diante da pandemia do COVID-19, em que todos os estabelecimentos comerciais, por decretos estadual e municipal, estão temporariamente fechados.

Os sujeitos entrevistados foram 2 gestores responsáveis pela contratação dos colaboradores selecionados para o projeto 40+ aplicados nas unidades da rede de cinemas na cidade de João Pessoa - PB. Vale ressaltar que uma das preocupações centrais desta investigação refere-se a manutenção do sigilo dos participantes do estudo e da empresa, para isso foram adotados nomes fictícios para que os respondentes se sentissem mais confortáveis e confiantes na partilha dos seus relatos. Além disso, o recurso do Ipsis Litteris foi empregado, procurando preservar e apresentar de maneira fidedigna todas as declarações proferidas, mesmo que constituídas de desvios de qualquer ordem, respeitando a originalidade do discurso. Segue no quadro 1 com o perfil dos entrevistados:

Quadro 1 - Perfil dos gestores entrevistados

\begin{tabular}{|l|l|l|l|l|l|}
\hline Gestores & Gênero & Idade & Escolaridade & Cargo em que Trabalha & Tempo de Empresa \\
\hline Gestor 1 & Masculino & 24 anos & Ensino Superior & $\begin{array}{l}\text { Subgerente } \\
\text { Administrativo }\end{array}$ & 3 anos e 9 meses \\
\hline Gestor 2 & Masculino & 24 anos & Ensino Superior & Gerente & 5 anos e 8 meses \\
\hline
\end{tabular}

Fonte: Elaboração Própria (2020)

E, por fim, para a análise dos dados, o método escolhido foi o da análise de conteúdo que, segundo Flick (2009), é uma técnica utilizada após a coleta de dados para realização da sua interpretação. Diante do exposto, para realização da análise, as informações coletadas foram subdivididas em categorias, sendo todas estas fundamentadas na revisão bibliográfica e nos objetivos específicos que apoiam a temática pesquisada, sendo elas: Modelo de contratação; Mercado de trabalho para a faixa etária acima dos quarenta anos; Acertos e 
Desafios do Programa 40+. As mesmas serão analisadas e discutidas na próxima seção.

\section{ANÁLISE E DISCUSSÃO DOS RESULTADOS}

Os resultados analisados seguem de acordo com as perguntas elaboradas baseadas nas categorias dispostas no roteiro utilizado para a presente pesquisa que relaciona a contratação de trabalhadores, com faixa etária acima dos quarenta anos, com o programa instituído para este fim dentro da organização estudada. A rede de cinemas investigada é considerada a maior operadora de cinemas da América Latina e as duas unidades estudadas na pesquisa em questão localizam-se em dois shoppings centers localizados na cidade de João Pessoa, empregando em sua totalidade 67 colaboradores.

A seguir, serão descritos os depoimentos coletados dos gestores das unidades localizadas na cidade de João Pessoa, os quais servirão de base para a análise. Tais depoimentos serão apresentados em categorias para um melhor entendimento.

\section{MODELO DE CONTRATAÇÃO}

De acordo com o questionamento 1, que trata do programa de contratação $40+$ os gestores informaram que este é utilizado da seguinte forma:

\footnotetext{
Gestor 1: "O programa deu início no segundo semestre de 2019, através da gerente de Rh Brasil. Consiste em ter uma porcentagem do total de colaboradores, profissionais com mais de quarenta anos. Sendo que colaboradores de serviços gerais com mais de quarenta anos não entraram nessa porcentagem, visto que já se tem alto índice de funcionários com mais de quarenta anos nesse setor. $\mathrm{O}$ intuito é dar oportunidade no setor de atendimento, onde tem se a maioria jovens. Assume-se uma responsabilidade social com o início desse projeto: realocar profissionais com essa idade no mercado de trabalho. Acredita-se também que trazer profissionais maduros e experientes é uma forma de diversificar o ambiente interno de trabalho e melhorar o atendimento para com os clientes".

Gestor 2: "É um programa de inclusão para pessoas, que muitas vezes possuem diversas experiências que possam agregar nosso dia a dia, mas por um certo preconceito, acabamos optando por pessoas mais novas, invalidando esses profissionais".
}

Nota-se, por meio das declarações, que a empresa disponibiliza uma porcentagem do total de seus colaboradores para que haja a contratação no programa $40+$, sendo as vagas disponibilizadas para esse público no setor de atendimento. Os gestores acreditam ainda que a recolocação no mercado de trabalho dos profissionais dessa faixa etária acaba por diversificar o ambiente de trabalho. Tal pensamento corrobora com a visão de Minarelli (2009), que afirma que as empresas têm adotado novos modelos organizacionais, adaptando-se de forma mais frequente as mudanças do mercado de trabalho. Um exemplo disso, é o aumento da inserção de trabalhadores com idade mais avançada, demonstrando uma postura inovadora adotada 
pela empresa, na qual mostra que a experiência do candidato é valorizada.

A segunda questão, que tratou do método de recrutamento da empresa e o modo como os gestores tiveram conhecimento da vaga que ocupam atualmente, foram obtidas as seguintes respostas:

Gestor 1: "A responsabilidade da divulgação fica em responsabilidade de cada cinema. O Rh da unidade define o melhor meio de divulgar de acordo com a realidade de cada cidade. Geralmente ocorre via internet, porém temos um hábito natural de divulgação interna, onde nossos próprios colaboradores fazem essa divulgação boca a boca."

Gestor 2: "Aplicamos informativos no painel do RH para que os próprios colaboradores divulguem, mas também postamos em sites de recrutamento, grupos de mensagens instantâneas."

Percebe-se que os métodos de recrutamento mais descritos foram por meio de grupos e sites utilizados para este fim. Vale ressaltar que Silva, Leal e Soares Neto (2018) classificam esse processo como sendo o recrutamento externo, no qual a organização busca por mão de obra de candidatos que não estejam ligados a empresa. Porém, este ressalta ainda que tal método nem sempre é eficaz, pois não há como garantir que os candidatos são as pessoas adequadas a vaga oferecida. Em contrapartida, Ferreira (2014), acredita que por meio do trabalho de uma pessoa especialista em Gestão de pessoas, o candidato poderá ser melhor avaliado, devido a aplicação de estratégias utilizadas durante esse processo.

No que refere-se ao processo de seleção realizado para que haja a contratação no programa $40+$ os gestores informaram que:

Gestor 1: “O projeto é novo, criado pela RH matriz (em São Paulo), até então ainda está em seu desenvolvimento, ou seja, ainda é preciso estabelecer processos padrões para este tipo seleção, é preciso mais debates com a Matriz, mais comunicação, para tornar esse projeto mais eficaz. Por hora, seguimos o mesmo método adotado nas contratações comuns (qualificações educacionais, entrevista e exercício teórico)."

Gestor 2: "Aplicamos prova de conhecimentos gerais e uma dinâmica em grupo/individual e entrevista com Gestor."

O processo de seleção adotado pela empresa em questão ocorre basicamente por meio da aplicação de testes de conhecimento geral e entrevista o que, de acordo com Figueiras et al. (2018), ão instrumentos que visam obter êxito no processo de recrutamento e seleção, sendo selecionado por estes meios o candidato mais qualificado para o cargo.

\section{MERCADO DE TRABALHO PARA A FAIXA ETÁRIA ACIMA DOS 40 ANOS}

Com relação às principais dificuldades encontradas por pessoas acima dos quarenta anos para ingressar no mercado de trabalho, os gestores destacaram na quarta questão:

Gestor 1: "As atividades no mercado de trabalho tornaram-se mais dinâmicas, enérgicas e mutáveis. No setor de Serviços podemos dizer que exista um receio em o colaborador não acompanhar o ritmo dos demais, o ritmo da rotina. E falando dos 
setores de forma geral, com o avanço da tecnologia tais profissionais podem não se adaptar ao novo, podem ter dificuldade de aprendizado etc. Afinal as coisas mudam numa velocidade tão surpreendente que ideias de dez anos atrás, não possuem mais eficiência hoje".

Gestor 2: "Uso da tecnologia nas empresas. Consigo perceber que essas pessoas com $40+$ sempre demonstram um pouco de dificuldade com isso...Mas com dedicação e persistência, exercem um excelente trabalho".

Observa-se que a principal dificuldade relatada pelos gestores está relacionada ao uso de tecnologias por pessoas dessa faixa etária, tendo em vista que tais ferramentas são recentes e muitos deles não tiveram acesso se comparado a gerações mais jovens. Tal fato é semelhante ao que foi visto por Bulla e Kaefer (2003), que acrescentaram aos motivos que atrapalham o ingresso dessas pessoas no mercado de trabalho a própria idade dos mesmos, assim como a falta de experiência tecnológica que, em alguns casos, acaba gerando um preconceito por parte da equipe.

No que refere-se aos pontos positivos e negativos relacionados à contratação de pessoas com idade acima dos quarenta anos, os gestores informaram na quinta questão que estes poderiam ser:

Gestor 1: "A dificuldade maior seria o entrosamento com profissionais jovens, tal relação é propensa a conflitos. O ponto positivo além de ser uma responsabilidade social é ter na equipe pessoas mais maduras, mais experiência pode trazer um equilíbrio de comportamento interno que é bom pra empresa. Acredito também que profissionais mais experientes possuem melhor "tato" com os clientes".

Gestor 2: "Positivo posso citar as diversas experiências que somam conosco, e negativo posso citar a falta de conhecimento tecnológico".

Através do que foi retratado pelos gestores foi possível identificar diversos pontos positivos na contratação de pessoas com idade acima dos quarenta anos. Dentre estes, podese destacar que a experiência obtida por esses profissionais foi item comum nas declarações apresentadas. Neri (2014) afirma que as pessoas dessa faixa etária costumam utilizar essas experiências como forma de serem recolocadas no mercado de trabalho, além de demonstrarem, de forma frequente, que estão aptos a realizarem as atividades destinadas a eles.

Candidatos com idade acima dos quarenta anos, geralmente, têm dificuldades em ingressar no mercado de trabalho. Na sexta questão, ao serem questionados a respeito de como esse público pode tornar-se uma opção de contratação mais atrativa para o mercado de trabalho os gestores relataram que:

Gestor 1: "É necessário manter-se atualizado as tecnologias, as necessidades da sociedade, a moda, as ideias do senso comum. Tudo que sofre mutações afetará os vários setores do mercado, e é necessário mudar junto com o mundo ao seu redor". Gestor 2: "Todas as pessoas com idade acima dos 40 possuem a chance de contratação, basta apenas mostrar as diversas competências que possuem, junto com uso da tecnologia". 
Como já foi citado, um grande ponto negativo na contratação de pessoas dessa faixa etária refere-se às dificuldades da utilização das tecnologias no ambiente de trabalho, o que também é levantado pelos entrevistados. Entretanto, Neri (2014) destaca que cada vez mais esse público vem se interessando em atualizar-se quanto ao uso das tecnologias, buscando assim aumentar as chances de conseguir a vaga disponível.

\section{ACERTOS E DESAFIOS DO PROGRAMA 40+}

No questionamento 7 , ao serem perguntados a respeito dos benefícios que 0 programa $40+$ oferece aos colaboradores, os gestores apontaram que:

Gestor 1: "A oportunidade de se realocar no mercado de trabalho é maior benefício de todos".

Gestor 2: "Inclusão de mais pessoas ao mercado de trabalho".

Com base nas afirmações dos gestores, verifica-se que o principal benefício relacionado a inclusão de programas como o 40+ é a reinserção de profissionais com idade avançada no mercado de trabalho. Diante do aumento da procura de trabalho por profissionais dessa faixa etária, percebe-se que o mercado vem aderindo a projetos que envolvam esse público. Batista (2016) cita que empresas que ofertam esse tipo de serviço, além de destinar vagas a esses profissionais também oferecem oportunidade de alcance de cargos melhores, demonstrando que o importante não é a idade dos funcionários, mas a qualificação dos mesmos.

Na questão 8, que aborda a relação da equipe de profissionais que participa atualmente do programa 40+ e sobre como é o trabalho desenvolvido por ela, os gestores relataram que:

\footnotetext{
Gestor 1: "Atualmente temos um atendente com 40+ e o trabalho exercido sempre foi referência aos demais, pois está conosco tem um bom tempo, conhecendo todos os processos e técnica de vendas. Está conosco na venda de produtos na bomboniere, e sempre consegue fazer o cliente levar algo mais do que só uma pipoquinha, rsrsrs". Gestor 2: "São pessoas que compreendem melhor situações mais estressantes, possuem um comportamento amigável com todos, mostram-se aptos a qualquer ocasião, participam quase $100 \%$ de qualquer atividade em grupo, sejam reuniões, dinâmicas, ou campanhas de venda, lidam com os clientes de forma carismática e abraçam os valores da empresa".
}

De acordo com os gestores das unidades em estudo, o bom comportamento dos funcionários do Programa 40+ acaba afetando de forma bastante positiva na relação dos mesmos com os demais funcionários, além da participação e proatividade que foram destacadas nas respostas. Neri (2014) destaca a necessidade de que esses profissionais busquem cada vez mais competências que venham a contribuir com o seu trabalho. Para isso, estes podem buscar participar de treinamentos, cursos de atualização profissional e digital, dentre outras atividades. 
A última questão procura avaliar, dentre os principais desafios enfrentados pelo programa 40+, o que os gestores fariam para melhorar a execução do projeto. Eles informaram que:

Gestor 1: "Faltam processos (recrutamento e seleção) padronizados e voltados apenas para esse profissional alvo, óbvio que tais processos precisam garantir e eficácia já antes testada. Falta mais comunicação com a matriz e com as outras unidades, essa troca de ideia seria boa para implementar ações que talvez alguns cinemas façam e outros não".

Gestor 2: "Atualmente é a divulgação das vagas. Mesmo com tanta tecnologia, as informações ainda acabam demorando um pouco para chegar até eles".

Conforme citado pelos gestores ainda existem muitos desafios a serem enfrentados pelo programa em questão, principalmente no que refere-se aos processos de recrutamento e seleção. O principal motivo apontado pelos gestores para essa dificuldade relacionada ao recrutamento ocorre devido a divulgação das vagas que, na maioria das vezes, é realizada por meio da internet, ferramenta pouco utilizada pelo público-alvo do programa 40+. Apesar dos desafios, Lajolo (2018), ressalta que iniciativas como esta são de grande importância e devem cada vez mais serem expandidas, de forma a provocar uma grande mudança na mentalidade do mercado de trabalho.

\section{CONSIDERAÇÕES FINAIS}

A presente pesquisa buscou analisar como uma rede de cinemas investe em um programa de contratação voltada a pessoas acima dos quarenta anos. Para isso, formulou-se a seguinte problemática: como uma rede de cinemas investe em um programa de contratação voltada a pessoas acima dos quarenta anos?

Dessa forma, procurou-se responder aos três objetivos específicos, sendo o primeiro deles, verificar como funciona o processo de Recrutamento e Seleção (R \& S) adotado pela rede de cinemas para a faixa etária pesquisada. Com relação ao método de recrutamento e seleção, observou-se uma importante preocupação dos próprios gestores quanto à forma como o processo em si vem sendo realizado. Na maioria das vezes, ele é feito por meio da divulgação de vagas em sites e grupos de mensagens dedicados a este fim. Sendo assim, destaca-se a necessidade da busca por novos meios de divulgação de vagas para este programa, haja visto que o público-alvo do mesmo geralmente apresenta dificuldade quanto ao uso de ferramentas tecnológicas.

O segundo objetivo específico procurou identificar o alinhamento da política de contratação da organização estudada em relação ao que vem sendo praticado no mercado de trabalho. No que refere-se a esse aspecto, verificou-se que a empresa em questão destina parte da porcentagem do seu quadro de funcionários ao Programa 40+, no qual são contratadas 
pessoas com idade acima dos quarenta anos. Apesar de vários pontos positivos terem sido relacionados à contratação de pessoas dessa faixa etária, cabe apontar que ainda há uma preocupação associada à dificuldade do público-alvo do programa no uso de tecnologias. Diante disso, evidencia-se a importância da realização frequente de recursos como: cursos de capacitação, oficinas, workshops, entre outros, como forma de melhorar cada vez mais a atuação desses profissionais dentro da empresa.

No terceiro objetivo específico, buscou-se examinar as potencialidades e fragilidades encontradas no Programa 40+ e foi percebido que, embora exista dificuldades vivenciadas pelo programa, este ainda vem sendo um projeto que deve seguir como referência para demais empresas, uma vez que pode ser considerado como um projeto inclusivo, oferecendo oportunidade de realocação dos profissionais com idade mais avançada.

Diante disso, referente ao objetivo geral, analisar como uma rede de cinemas investe em um programa de contratação voltada a pessoas acima dos quarenta anos foi possível averiguar a importância do Projeto 40+ para a empresa em questão. Diante das declarações obtidas, percebe-se que os funcionários que fazem parte deste projeto acabam por melhorar o funcionamento da organização por meio das experiências já obtidas e pelo comportamento mais maduro. No entanto, ainda existem desafios a serem superados, como, por exemplo, o maior deles: a dificuldade do conhecimento tecnológico desse público, que acaba por influenciar, até mesmo, o próprio processo de recrutamento e seleção da empresa, tornandoo mais desafiador.

Assim, com base no exposto, como contribuição, o trabalho procurou frisar no meio acadêmico a possibilidade de enriquecimento da temática para a literatura com a produção deste estudo, no intuito de incentivar e motivar a produção de outras pesquisas sobre a área. Para a administração, ou o mercado em si, o trabalho busca ressaltar que a criação de projetos dessa natureza valoriza a política de diversidade de profissionais, o que acaba tornando as empresas, de modo geral, mais acessíveis. E, por fim para a sociedade, este estudo destaca e traz como reflexão que as pessoas com idade mais avançada devem ser submetidas a tratamento similar às demais faixas etárias no mercado de trabalho, de forma que a idade não seja um fator negativo para a contratação. Tal constatação é feita mediante a possibilidade de habilidades semelhantes ou até mais expressivas surgirem nesses profissionais em relação aos de idade inferior.

Com relação aos fatores limitadores da pesquisa, o item mais desafiador concentrouse na coleta de dados. Inicialmente, as pesquisadoras tinham como propósito aplicar a entrevista de modo presencial, o que poderia gerar respostas mais elaboradas por parte dos entrevistados. Todavia, em detrimento do cenário de pandemia vivenciado no momento da elaboração da presente pesquisa, o modus operandi acabou por ser alterado, direcionando a aplicação do roteiro de entrevista de forma digital. 
Para concluir, como sugestões de estudos futuros, este estudo recomenda que a mesma temática possa ser abordada em outros contextos regionais. Além disso, este estudo traz como propositura a possibilidade de pesquisadores da área de Recursos Humanos trabalharem a questões relativas a permanência e o desenvolvimento de profissionais com a faixa etária acima dos quarenta anos contratados por programas de natureza similar ao 40+.

\section{REFERÊNCIAS}

ABDALA, V. Cerca de $25 \%$ dos desempregados procuram emprego há mais de dois anos. Empresa Brasil de Comunicação (EBC), Rio de Janeiro, 14 de fev. de 2020. Disponível em: $<$ http://agenciabrasil.ebc.com.br/economia/noticia/2020-02/cerca-de-25-dosdesempregados-procuram-emprego-ha-mais-de-dois-anos>. Acesso em: 27 fev. 2020.

AYLMER, R. Maturidade do raciocínio moral. Associação Brasileira de Recursos Humanos (ABRH), São Paulo, 10 de jun. de 2019. Disponível em:

<https://www.abrhbrasil.org.br/cms/materias/artigos/maturidade-do-raciocinio-moral/> Acesso em: 27 mar. 2020.

BANOV, M. R. Recrutamento, seleção e competências. 4. ed., São Paulo: Atlas, 2015.

BARDUCHI, A. L. J. Empregabilidade: competências pessoais e profissionais. São Paulo: Pearson Prentice Hall, 2010.

BATISTA, P. H. A. Dificuldades do Trabalhador com mais de Quarenta Anos diante do Mercado de Trabalho. Revista Brasileira de Gestão e Engenharia, [S.I.], n. 13, p. 01-22, jan./jun. 2016.

BULLA, L. C.; KAEFER, C. O. Trabalho e Aposentadoria: as repercussões sociais na vida do idoso aposentado. Revista Virtual Textos \& Contextos, Porto Alegre, v. 2, n. 2, p. 01-08, dez. 2003.

CAMPOS, A.; BARSANO, P. B. Administração: guia prático e didático. 2. ed., São Paulo: Érica, 2016.

CAXITO. F.A. Recrutamento e Seleção de Pessoas. 1. Ed. Curitiba: IESDE, 2007.

DIGITAL GROUP. Portal. Disponível em: < https://dotgroup.com.br/pt/blog/infografico-asgeracoes-e-suas-formas-de-aprender> Acesso em: 18 jul. 2020.

FAISSAL, R.; PASSOS, A. E. V. M.; MENDONÇA, M. C. F.; ALMEIDA, W. M. C. Atração e Seleção de Pessoas. 3. ed., Rio de Janeiro: FGV, 2015.

FARIA, B. P. Fatores que motivam os jovens da geração $Z$ nas organizações. 2016. 53 f. Monografia (Bacharelado em Administração) - Faculdade de Economia, Administração e Contabilidade, Universidade de Brasília, Brasília.

FERREIRA, P. I. Atração e seleção de talentos. Rio de Janeiro: LTC, 2014. 
FIGUEIRAS, B. S.; FELISBINO, G. S.; FELIZARDO, T. A. P.; FONSECA, B. G. A importância do recrutamento e seleção na organização: tipos de entrevista. São Paulo. 2018.

FLICK, U. Métodos de Pesquisa: introdução à pesquisa qualitativa. 3. ed. Porto Alegre: Artmed, 2009.

FOLHA DE SÃO PAULO. Empresas abrem vagas só para profissionais maduros. Folha de São Paulo, 04 de mar. de 2018. Disponível em:

<https://www1.folha.uol.com.br/mercado/2018/03/empresas-abrem-vagas-so-paraprofissionais-maduros.shtml>. Acesso em: 13 mar. 2020.

GIL, A. C. Método e técnicas de pesquisa social. 6. ed. São Paulo: Atlas S.A, 2008.

KNECHTEL, M. R. Metodologia da pesquisa em educação: uma abordagem teórico-prática dialogada. Curitiba: Intersaberes, 2014.

LAKATOS, E. M.; MARCONI, M. A. Fundamentos da metodologia científica. 7. Ed. São Paulo: Atlas, 2010.

LAJOLO, M. Empresas criam programas de contratação pra maiores de 50 anos. Veja, 15 de out. de 2018. Disponível em: <https://veja.abril.com.br/economia/empresas-criamprogramas-de-contratacao-para-maiores-de-50-anos/> Acesso em: 27 mar. 2020.

MARQUES, J. C. Gestão de Recursos Humanos. São Paulo: Cengage, 2016.

MINARELLI, J. A. Empregabilidade. São Paulo: Gente, 2009.

NERI, A. Gestão de RH por competência e a empregabilidade, Campinas: Papirus, 2014. Disponível em:

<https://books.google.com.br/books?id=kneADwAAQBAJ\&printsec=frontcover\&hl=pt-

$B R \&$ source=gbs_ge_summary_r\&cad=0\#v=onepage\&q\&f=false $>$ Acesso em: 13 mar. 2020.

ORLILKAS, E. Consultora interna de RH. Conceitos, benchmarking, cases - o modelo de gestão com as pessoas que as empresas bem-sucedidas estão utilizando. 10. ed. São Paulo: Ibpex, 2001.

RAPOSO, D. S. P.; GÜNTHER, I. A. O ingresso na universidade após os 45 anos: um evento nãonormativo. Psicologia em Estudo, Maringá, v. 13, n. 1, p. 123-31, jan./mar. 2008. Disponível em: <http://www.scielo.br/scielo.php?script=sci_arttext\&pid=S1413-

73722008000100015\&lng=en\&nrm=iso\&tlng=pt>. Acesso em: 27 mar. 2020.

SANTOS, S. S.; LIMA, T. B. A relação da tecnologia com o processo de recrutamento e seleção de pessoal a partir da visão de gestores de três hotéis de João Pessoa, Paraíba/PB, Brasil.

Turismo e Sociedade, v. 11, n. 2, 2018.

SILVA, M. F.; LEAL, J. S.; SOARES NETO, J. B. TEMOS VAGAS! Um Estudo da Percepção dos Resultados nos Processos de Recrutamento e Seleção via Plataformas Digitais. O Eco da Graduação, v. 3, n. 2, p. 43-43, 2018. 
STOPAZZOLI, L. C.; PUMARIEGA, Y. N. O papel do psicólogo no processo de seleção e recrutamento de pessoas. 2020. Trabalho de Conclusão de Curso (Graduação em Psicologia) Faculdade de Educação e Meio Ambiente - FAEMA, 2020. 